\title{
A new approach to publishing research papers in the Journal
}

After discussions with our Editorial Board, consultation with trainees and seasoned GPs, and a survey of the academic departments of general practice and primary care, we have decided to begin to implement a new policy on the publication of original articles accepted for publication in the BJGP. Fully-proofed and citeable versions of papers will be posted on the $B J G P$ electronic journal site as soon as possible after acceptance - continuous electronic publication - and a shorter version will appear in the next available issue of the paper Journal. The printed version provides a concise and easilyread summary of the main findings of the study. This will include an account of the significance of the research and its implications for practice, clear graphics, and tabulated information which will allow rapid appraisal by readers who can then follow up their interest in the paper by accessing the full version on the web.

There are many reasons for taking this decision. The first and perhaps most compelling is the changing balance between electronic and paper publication across the whole of medical publishing, related to the increased use of online resources and the need to manage the ever-increasing volume of biomedical knowledge. The second is speed of publication: most authors want to see their work 'out there' as soon as possible and, even with a speedy peer review and manuscript handling system, the wait for space in the paper publication can be a source of frustration. Third, there is increasing evidence that the readability and the readership of original papers can be improved if the paper version is shorter, and this approach has already been adopted by other publications in our field. Fourth, a paper-only paradigm places restrictions on the number of papers that can be published and paper production costs are high. We receive more good papers than we can currently find space for and our new strategy will enable us to publish more material without compromising quality or citation rates. The approach taken for original research will, in time, apply to our policy on clinical reviews, guidelines, and systematic reviews, where we will offer full online publication at about the same time as paper publication of a linked summary or editorial.

The paper Journal remains very important. We know that readers appreciate the convenience, portability, feel, and familiarity of paper publications, and at present very few readers of the $B J G P$ and other College publications do their reading online: papers for detailed study are generally downloaded and printed from the website. In addition to the two-page summaries of research papers, we plan to continue to provide authoritative, provocative, and informative editorials and articles on clinical, educational, policy, and research issues of importance to the profession, and also continue to give all interested in general practice and primary care a platform on which to contribute to the debate.

Following a major review of the Journal in 2009 , we anticipate further changes in the publication over the months ahead, including re-design of the paper Journal and better integration and linkages between the Journal website and other College publications and outputs to enhance its contribution to training and continuing professional development, as well as to research and education.

The 'Instruction for Authors' have been modified to take account of these changes and can be accessed on the BJGP website (http://www.rcgp.org.uk/bjgp). We welcome feedback on our new arrangements and proposals.

\section{Roger Jones \\ Editor, BJGP}

\section{Provenance}

Freely submitted; not peer reviewed.

DOI: 10.3399/bjgp10X502092

\section{ADDRESS FOR CORRESPONDENCE}

\section{Roger Jones}

British Journal of General Practice, Royal College of General Practitioners, 14 Princes Gate, London, SW7 1PU E-mail: journal@rcgp.org.uk 